\title{
CONTRIBUIÇÃO AO ESTUDO DOS RAMOS ARTERIAIS HILARES, JUSTAHILARES E EXTRAHILARES EM RINS DE CAVALOS (EQUUS CABALLUS) \&
}

Pereira, J. G. L. - Contribuição ao estudo dos ramos arteriais hilares, justahilares e extrahilares em rins de cavalos (Equus caballus). Rev. Fac. Med. vet. Zootec. Univ. S. Paulo, $11: 237-61,1974$

Resumo: O trabalho baseia-se no exame de 90 conjuntos abrangendo rins, vasos, ureteres e tratos correspondentes da artéria aorta e veia cava caudal, retirados de cavalos adultos, 12 machos $e 18$ fimeas, nos quais estudaram-se os ramos hilares, justahilares e extrahilares da artéria renal, bem como o comportamento global destes ramos tomados isoladamente.

Os resultados permitem chegar îs seguintes conclusōes:

1. Entram de trés a dez ramos da artéria renal direita na regiāo hilar; à esquerda de três a onze;

2. Contam-se um a seis ramos das artérias renais direita e esquerda a ocuparem posiçăo justahilar. Em 1 caso dे direita, inexistiam vasos justahilares;

3. Computam-se um a quinze ramos da arteria renal direita a aprofundarem-se na zona extrahilar; $\grave{a}$ esquerda registram-se um a dezoito;

4. Na região hilar, as ramos da artéria renal são, em maior numero, periféricos;

5. Na regiāo justahilar, os ramos da arteria renal são predominantemente centrais;

6. Na região extrahilar, os ramos da artéria renal são prevalentemente centrais;

7. A artéria renal exibe igual número de ramos, bilateralmente, em 6 preparaçöes;

8. Há correlação positiva, tanto para o rim direito quanto para o esquerdo, entre o numero de ramos hilares, justahilares e extrahilares, independentemente do sexo, estatisticamente.

UnITERMos: Cavalos *; Rins *; Artéria renal *.

\$ Tese apresentada a Escola Paulista de Medicina para a obtençăo do titulo de Mestre. Trabalho apresentado ao $\mathrm{X}$ Congresso Brasilelro de Anatomia, reallzado em Săo Paulo, de 21 a 26 de Julho de 1974 .

- Professor Assistente Doutor.

Departamento de Cirurgla e Obstetricla da Faculdade de Medicina Veterinária e Zootecnia da USP. 
PEREIRA, J. G. L. - Contribulçao ao estudo dos ramos arterials hilares, justahilares c extrahllares em rins de cavalos (Equus caballus). Rev. Fac. Med. vet. Zootec. Univ. S. Paulo, $11: 237-61,1974$.

\section{INTRODLCAOO F. LITERATURA}

A pesquisa ora apresentada vem dar seqüência aos trabalhos realizados no âmbito das disciplinas de Anatomia Descritiva e Anatomia Topográfica da Faculdade de Medicina Veterinária e Zootecnia da Universidade de Sāo Paulo, com vistas à disposição dos vasos renais. Desta vez o tema escolhido versa sobre o número e os locais de entrada dos ramos hilares, justahilares e extrahilares da artéria renal.

Se nos surpreendeu a falta de informaçōes relativas ao assunto, na literatura especializadia ao nosso alcance, não deixou de causar-nos estranheza e escassez de dados nos compéndios de Anatomia Veterinária, particularmonte a levar-se em conta o fato de que muitos deles servem-se, para suas descriçōes, dos equídeos, como padrão. De assinalar-se, também, a pobresa de esclarecimentos, por parte dos livros de textos consagrados apenas ao estudo da espécie eqüina.

Com efeito, quanto ao número de ramos da artéria renal, CARADONNA 6 (1930). FAVILLI ${ }^{10}$ (1931) e BOSSI ${ }^{1}$ (s.d.), registrem dois ou três; MANNU 18 (1930), faz menção à existência de quatro a seis; GURLT'S 13 (1873), ELLENBERGER \& BAUM $^{9}$ (1932), BRUNI \& ZIMMERL ${ }^{5}$ (1947), SISSON \& GROSSMAN 27 (1959) e SCHWARZE \& SCHRODER 26 (1972), indicam cinco a oito; BRADLEY + (1922), apresenta seis a oito; FRANCK 11 (1883), MONGIARDINO 22 (1903), MARTIN 13 (1904), MARTIN 20 (1915), MONTANE \& BOURDELLE 23 (1913), LEPOUTRE 16 (1921), LESBRE 17 (1923), SCHMALTZ 24 (1928), BOURDELLE \& BRESSOU ${ }^{3}$ (1938), ZIMMERL 29 (1949), SCHUMMER \& NICKEL 25 (1960), DOBBERSTEIN \& HOFFMANN i (1963), DOBBERSTEIN \& HOFFMANN 8 (1963), KOCH ${ }^{14}$ (1963) e KOCH 15 (1965), aludem a vários e, finalmente, ZANOLLI 28 (1910), BOURDELLE \& BRESSOU 2 (1937), MASSUI 21 (1960) e GON-
ZALFZ Y GARCIA \& ALVAREZ 12 (1961), como todos os precedentes tratadistas, dizem que a artéria renal atinge o hilo do órgão, não esclarecendo, todavia, no tocante às suas divisōes.

Dentre os AA. citados, acrescente-se, GURLT'S ${ }^{13}, \quad$ FRANCK ${ }^{11}$, MARTIN ${ }^{19}$, MARTIN 20, BRADLEY *, LESBRE 17, SCHMALTZ ${ }^{24}$, ELLENBERGER \& BAUM 9 , SISSON \& GROSSMAN 2i e SCHWARZE \& SCHRUDER 26 são os úni$\cos$ a elucidar que ramificaçóes daquele vaso penetram no rim pela face ventral.

\section{MATERIAL E METODO}

Utilizamo-nos, neste trabalho, de 60 rins, retirados de 30 cavalos sem raça definida, 12 machos e 18 fêmeas, todos adultos, abatidos no Matadouro de Fqüideos Primeat, em Bragança Paulista, Estado de São Paulo.

Os pares de peças, ainda unidos pelos tratos da aorta e da veia cava caudal, foram dissccados, depois de submetidos à fixaçāo mediante injeção de formol (soluçāo aquosa a 10\%); de cada unidade fizemos, a seguir, desenho esquemático.

Exposto o hilo, procuramos definir as áreas hilares, justahilares e extrahilares, valendo-nos de duas linhas imaginárias, traçadas de maneira a demarcar na super. ficie do orgão a orientação a observar caso pretendessemos dividí-lo, por meio de cortes, nas metades dorsal e ventral (a primeira) e nas porções cranial e caudal (a segunda). Tais linhas, perpendiculares, cruzar-se-iam na borda lateral do rim, e na medial, exatamente em correspondencia ao centro do orifício resultante da secção transversa justarenal do ureter.

Uma vez identificados os quatro territórios, a que aplicamos as qualificaçōes de craniodorsal, cranioventral, caudodorsal e caudoventral, tomamo-los como base pa- 
PEREIRA, J. G. L. - Contributço ao estudo dos ramos arterlais hllares, justahilares e extrahllares em rins de cavalos (Equtts caballus). Rev. Fac. Med. vet. Zootec. Univ. S. Paulo, 11 : 237-61, 1974 .

ra assinalação do número e locais de entrada dos ramos da artéria renal, consoante critério bem evidenciado nos desenhos. De fato, eles mostram-nos, além das referidas linhas, quatro circunferências concêntricas, a menor das quais simboliza o ureter; as três restantes delimitam, a contar do centro, coroas figurativas, respectivamente, das áreas hilar, justahilar e extrahilar, representadas em todos os quadrantes. Estes, assim como os doze distintos setores ora reconheciveis, receberam, aliás, as mesmas denominações dos territórios que integram.

Torna-se quase desnecessários acrescentar, finalmente, que os esquemas, nos quais nāo indicamos a veia renal, sempre única e posta dorsalmente ao ureter, apresentamnos os rins como se os tivéssemos sujeitos a giro de $90^{\circ}$, no sentido mediolateral.

R E S U T T D O S

Respeitando-se circunferências e quadrantes traçados para os fins direito $e$ esquerdo, passamos a discorrer sobre 0 número e os locais de penetração dos ramos hilares, justahilares e extrahilares da artéria renal, reproduzidos nos esquemas de 1 a 30 .

I. Rim direito

A. Ramos hilares

1. Em 8 preparaçōes $(26,7 \% \pm 8,1)$, pertinentes a 4 fêmeas e 4 machos, notamos cinco vasos, assim disposto:

a. quadrante cranioventral - um - 2 vezes, dois -3 vezes, três - 2 vezes, quatro - 1 vez;

b. quadrante craniodorsal - um - 1 vez;

c. quadrante caudoventral - um - 3 vezes, dois -3 vezes, três -2 vezes; d. quadrante caudodorsal $-u m-1 \mathrm{vez}$;

e. linha craniocaudal - entre os quadrantes cranioventral e caudoventral, um - 4 vezes

f. linha dorsoventral - entre os quadrantes cranioventral e cranjodorsal, um -1 vez.

2. Em 7 peças $(23,3 \% \pm 7,7)$, correspondentes a 6 fêmeas e 1 macho, assinalamos quatro vasos, colocados da seguinte forma:

a. quadrante cranioventral - um - 3 vezes, dois - 3 vezes, três - 1 vez;

b. quadrante craniodorsal - um - 1 vez;

c. quadrante caudoventral - um - 3 vezes, dois -2 vezes;

d. linha craniocaudal - entre os quadrantes cranioventral e caudoventral, um - 4 vezes;

e. linha dorsoventral - entre os quadrantes caudoventral e caudodorsal, um - 3 vezes e entre os quadrantes cranioventral e craniodorsal, um 1 vez.

3. Em 4 dissecções $(13,3 \% \pm 6,2)$, relativas a 2 fêmeas e 2 machos, vimos três vasos, situados desta maneira:

a. quadrante cranioventral - um - 3 vezes, dois - 1 vez;

b. quadrante caudoventral - um - 3 vezes;

c. linha craniocaudal - entre os quadrantes cranioventral e caudoventral, um -3 vezes;

d. linha dorsoventral - entre os quadrantes caudoventral e caudodorsal, um - 1 vez. 
PEREIRA, J. G. L. - Contribulçao ao estudo dos ramos arterlals hilares, Justahilares e extrahilares em rins de cavalos (Equus caballus). Rev. Fac. Med. vet. Zootec. Univ. S. Paulo, $11: 237-61,1974$.

4. Em 3 órgãos $(10,0 \% \pm 5,5)$, pertencentes a 2 fêmeas e 1 macho, computamos nove vasos, assim distribuídos:

a. quadrante cranioventral - quatro 3 vezes;

b. quadrante craniodorsal - três -1 vez;

c. quadrante caudoventral - um -1 vez;

d. quadrante caudodorsal - um -1 vez;

e. linha craniocaudal - entre os quadrantes cranioventral e caudoventral, um -3 vezes;

f. linha dorsoventral - entre os quadrantes caudoventral e caudodorsal, um - 2 vezes e entre os quadrantes cranioventral e craniodorsal, um 2 vezes.

5. Em 3 casos $(10,0 \% \pm 5,5)$, retirados de 1 fêmea e 2 machos, patenteamos dez vasos, com as seguintes localizaçōes:

a. quadrante cranioventral - três - 1 vez; quatro -1 vez, cinco -1 vez;

b. quadrante craniodorsal - um -2 vezes;

c. quadrante caudoventral - dois -1 vez, três -1 vez, quatro -1 vez;

d. quadrante caudodorsal - um - 2 vezes;

e. linha craniocaudal - entre os quadrantes cranioventral e caudoventral, um -1 vez, dois -1 vez e entre os quadrantes craniodorsal e caudodorsal, um - 1 vez;

f. linha dorsoventral - entre os quadrantes cranioventral e craniodorsal, um -1 vez.
6. Em 2 rins $(6,7 \% \pm 4,6)$, todos de fêmeas, reconhecemos seis vasos, assim postados:

a. quadrante cranioventral - dois -2 vezes;

b. quadrante caudoventral - três -1 vez, quatro -1 vez;

c. linha craniocaudal - entre os quadrantes cranioventral e caudoventral, um -1 vez.

7. Em 2 preparações $(6,7 \% \pm 4,6)$, referentes a 1 fêmea e 1 macho, registramos sete vasos, a saber:

a. quadrante cranioventral - quatro 2 vezes;

b. quadrante caudoventral - dois - 2 vezes;

c. linha craniocaudal - entre os quadrantes cranioventral e caudoventral, um -2 vezes.

8. $\operatorname{Em} 1$ peça $(3,3 \% \pm 3,3)$, pertinente a 1 macho, contamos oito vasos, dispostos desta maneira: três no quadrante cranioventral; dois no quadrante caudoventral; dois sobre a linha craniocaudal: entre os quadrantes cranioventral e caudoventral e entre os quadrantes craniodorsal e caudodorsal; um, sobre a linha dorsoventral, entre os quadrantes cranioventral e craniodorsal.

B. Ramos justahilares

1. Em 11 dissecçōes $(36,7 \% \pm 8,8)$, correspondentes a 6 fêmeas e 5 machos, notamos dois vasos, assim colocados:

a. quadrante cranioventral - um - 6 vezes, dois -3 vezes;

b. quadrante caudoventral - um -6 vezes, dois -2 vezes. 
PEREIRA, J. G. L. - Contribulçăo ao estudo dos ramos arteriais hilares, justahllares e extrahllares em rins de cavalos (Equus caballus). Rev. Fac. Med. vet. Zootec. Univ. S. Paulo, $11: 237-61,1974$.

2. Em 7 órgāos $(23,3 \% \pm 7,7)$, relativos a 4 fêmeas e 3 machos, assinalamos très vasos, situados da seguinte forma:

a. quadrante cranioventral - um -4 vezes, três - 1 vez;

b. quadrante caudoventral - um -4 vezes, três - 1 vez;

c. linha craniocaudal - entre os quadrantes cranioventral e caudoventral, um -2 vezes.

3. $\operatorname{Em} 4$ casos $(13,3 \% \pm 6,2)$, pertencentes a 3 fêmeas e 1 macho, vimos um vaso, assim distribuido:

a. quadrante cranioventral - 1 vez;

b. quadrante caudoventral -1 vez;

c. linha craniocaudal - entre os quadrantes cranioventral e caudoventral, 2 vezes.

4. $\mathrm{Em} 3$ rins $(10,2 \% \pm 5,5)$, retirados de 2 fêmeas e 1 macho, computamos quatro vasos, localizados desta maneira:

a. quadrante cranioventral - dois - 2 vezes, três - 1 vez;

b. quadrante caudoventral - um - 1 vez, dois -2 vezes.

5. Em 2 preparaçōes $(6,7 \% \pm 4,6)$, todas de fêmeas, patenteamos cinco vasos, a ocupar as posiçōes abaixo discriminadas:

a. quadrante cranioventral - dois -1 vez;

b. quadrante caudoventral - dois -1 vez, três - 1 vez;

c. linha craniocaudal - entre os quadrantes cranioventral e caudoventral, um -1 vez, dois -1 vez.
6. Em 2 peças $(6,7 \% \pm 4,6)$, ambas de machos, reconhecemos seis vasos, a saber:

a. quadrante cranioventral - três -2 vezes;

b. quadrante caudoventral - dois -1 vez, três - 1 vez;

c. linha craniocaudal - entre os quadrantes cranioventral e caudoventral, um -1 vez.

7. Em 1 dissecção $(3,3 \% \pm 3,3)$, referente a 1 fêmea, não registramos vasos.

C. Ramos extrahilares

1. Em 5 órgãos $(16,7 \% \pm 6,8)$, pertinentes a 4 fêmeas e 1 macho, notamos cinco vasos, dispostos desta forma:

a. quadrante cranioventral - três -1 vez, quatro -2 vezes, cinco -2 vezes;

b. quadrante caudodorsal - um -3 vezes;

c. quadrante caudodorsal - um -1 vez.

2. Em 4 casos $(13,3 \% \pm 6,2)$, correspondentes a 2 fêmeas e 2 machos, assinalamos dois vasos no quadrante cranioventral.

3. Em 3 rins $(10,0 \% \pm 5,5)$, relativos a 2 fémeas e 1 macho, vimos um vaso no quadrante cranioventral.

4. Em 3 preparaçōes $(10,0 \% \pm 5,5)$, pertencentes a 1 fêmea e 2 machos, evidenciamos três vasos no quadrante cranioventral.

5. Em 3 peças $(10,0 \% \pm 5,5)$, retiradas de 2 fêmeas e 1 macho, patenteamos treze vasos, colocados do seguinte modo: 
PEREIRA, J. G. L. - Contribulção ao estudo dos ramos arterlals hilares, justahilares e extrahilares em rins de cavalos (Equus caballus). Rev. Fac. Med. vet. Zootec. Univ. S. Paulo, $11: 237-61,1974$

a. quadrante cranioventral - doze -2 vezes, treze - 1 vez;

b. quadrante caudoventral - um - 2 vezes.

6. Em 2 dissecçōes $(6.7 \% \pm 4,6)$, referentes a 1 fêmøa e 1 macho, reconhecemos quatro vasos no quadrante cranioventral.

7. Em 2 órgãos $(6,7 \% \pm 4,6)$, pertinentes a 1 fêmea e 1 macho, registramos seis vasos no quadrante cranioventral.

8. Em 2 casos $(6,7 \% \pm 4,6)$, todas fêmeas, notamos oito vasos no quadrante cranioventral.

9. Em 2 rins $(6,7 \% \pm 4,6)$, correspondentes a 1 fêmea e 1 macho, assinalamos nove vasos, assim situados:

a. quadrante cranioventral - seis -1 vez, sete -1 vez;

b. quadrante caudoventral - dois -1 vez, três - 1 vez.

10. Em 1 preparação $(3,3 \% \pm 3,3)$, relativa a 1 macho, vimos sete vasos, distribuídos desta maneira: seis no quadrante cranioventral e um no quadrante caudoventral.

11. Em 1 peça $(3,3 \% \pm 3,3)$, pertencente a 1 fêmea, computamos dez vasos, assim localizados: nove no quadrante cranioventral e um do quadrante caudoventral.

12. Em 1 dissecção $(3,3 \% \pm 3,3)$, referente a 1 fêmea, patenteamos doze vasos, nas seguintes posições: onze ocupando o quadrante cranioventral e um o quadrante caudoventral.

13. Em 1 órgão $(3,3 \% \pm 3,3)$, retirado de 1 macho, reconhecemos quinze vasos, a saber: treze no quadrante cranioventral e dois no quadrante caudoventral.
Cabe-nos, completando a descriçāo, ressaltar a ausência de ramos hilares nos quadrantes caudoventral - 4 vezes; craniodorsal -25 vezes e caudodorsal -26 vezes.

Por outro lado, nāo haviam ramos arteriais justahilares nos quadrantes cranioventral -8 vezes e caudoventral -9 vezes; em todos os casos, os quadrantes craniodorsal e caudodorsal mostravam-se, outrossim, livres deles.

Enfim, inexistiam ramos arteriais extrahilares nos quadrantes caudoventral - 19 vezes e caudodorsal - 29 vezes; em todos os rins, também não os registramos no quadrante craniodorsal.

D. Comportamento global dos ramos hilares da artéria renal direita, tomados isoladamente

Os ramos hilares da artéria renal direita penetram em maior numero, vale dizer, 18 vezes $(60,0 \% \pm 8,9)$, na periferia da região; assinalamo-los, ainda, a se repartirem, por igual, no centro e na periferia, 6 vezes $(20,0 \% \pm 7,3)$ e a entrarem predominantemente no centro, 3 vezes $(\mathbf{1 0 , 0 \%} \pm 5,5)$. Nas restantes preparaçōes, a situação é, 2 vezes $(6,7 \% \pm 4,6)$, apenas periférica e 1 vez $(3,3 \% \pm 3,3)$, unicamente central.

E. Comportamento global dos ramos justahilares da artéria renal direita, tomados isoladamente

No que respeita aos ramos arteriais, justahilares, vimo-los: 10 vezes $(33,3 \% \pm$ 8,6 ), a povoarem prevalentemente a zona central; 8 vezes $(26,7 \% \pm 7,3)$, a exibirem distribuição equivalente; 3 vezes $(10,0 \% \pm$ $5,5)$, a localizarem-se exclusivamente na periferia; 2 vezes $(6,7 \% \pm 4,6)$, somente em posição central. Notamos ausência desses vasos, 1 vez $(3,3 \% \pm 3,3)$. 
PEREIRA, J. G. L. - Contribulção ao estudo dos ramos arteriais hllares, justahilares e extrahilares em rins de cavalos (Equus caballus). Rev. Fac. Med. vet. Zootec. Univ. S. Paulo, $11: 237-61,1974$.

F. Comportamento global dos ramos extrahilares da artéria renal direita, tomados isoladamente

A penetraçāo dos ramos extrahilares dáse 13 vezes $(43,3 \% \pm 9,0)$, predominantemente e 10 vezes $(33,3 \% \pm 8,6)$ apenas em distritos centrais; achamo-los, além do mais, igualmente repartidos, 4 vezes $(13,3 \%$ $\pm 6,2$ ) e com situaçāo periférica dominante, 3 vezes $(10,0 \% \pm 5,5)$.

\section{Rim esquerdo}

\section{A. Ramos hilares}

1. Em 12 peças $(40,0 \% \pm 8.9)$, referentes a 7 fêmeas e 5 machos, contamos cinco vasos, assim distribuidos:

a. quadrante cranioventral - um - 4 vezes, dois -4 vezes, três - 4 vezes;

b. quadrante craniodorsal - um - 2 vezes;

c. quadrante caudoventral - um - 1 vez, dois -7 vezes, três -2 vezes;

d. quadrante caudodorsal - um - 3 ve. zes, dois - 1 vez;

e. linha craniocaudal - entre os quadrantes craniodorsal e caudodorsal, um -1 vez:

f. linha dorsoventral - entre os quadrantes cranioventral e craniodorsal, um - 3 vezes e entre os quadrantes caudoventral e caudodorsal, um 4 vezes.

2. Em 6 dissecçös $(20,0 \% \pm 7,3)$, pertinentes a 4 fêmeas e 2 machos, registramos quatro vasos, localizados do seguinte modo:

a. quadrante cranioventral - um - 3 vezes;

b. quadrante craniodorsal - um - 2 vezes, dois - 1 vez; c. quadrante caudoventral - um - 5 vezes, três - 1 vez;

d. quadrante caudodorsal - um - 3 vezes, três - 1 vez:

e. linha craniocaudal - entre os quadrantes cranioventral e caudoventral, um - 1 vez;

f. linha dorsoventral - entre os quadrantes cranioventral e craniodorsal, um - 1 vez e entre os quadrantes caudoventral e caudodorsal, um -1 vez.

3. Em 5 órgāos $(16.7 \% \pm 6,8)$, correspondentes a 2 fêmeas e 3 machos, assinalamos trés vasos, postados desta forma :

a quadrante cranioventral - um - 3 vezes, dois - 2 vezes;

b. quadrante craniodorsal - um - 2 vezes;

c. quadrante caudoventral - um - 5 vezcs;

d. linha craniocaudal - entre os quadrantes craniodorsal e caudodorsal, um - 1 vez.

4. Em 4 casos $(13,3 \% \pm 6,2)$, todos de fêmeas, vimos seis vasos, a saber:

a. quadrante cranioventral - $\mathrm{um}-1$ vez, dois - 1 vez, três -2 vezes;

b. quadrante craniodorsal - um - 2 vezes, três - 1 vez;

c. quadrante caudoventral - um - 1 vez, dois - 2 vezes;

d. quadrante caudodorsal - dois - 1 vez;

e. linha craniocaudal - entre os quadrantes cranioventral e caudoventral, um - 1 vez; 
PEREIRA, J. G. L. - Contribulçăo ao estudo dos ramos arterlals hllares, Justahllares e extrahllares em rins de cavalos (Equus caballus). Rev. Fac. Med. vet. Zootec. Univ. S. Paulo, $11: 237-61,1974$.

1. linha dorsoventral - entre os quadrantes cranioventral e craniodorsal, um - 1 vez;

5. Em 1 rim $(3,3 \% \pm 3,3)$, pertencente a 1 macho, notamos sete vasos, colocados da seguinte maneira: dois no quadrante cranioventral; dois no quadrante caudoventral; um no quadrante caudodorsal e dois sobre a linha dorsoventral, entre os quadrantes cranioventral e craniodorsal e entre os quadrantes caudoventral e caudodorsal.

6. Em 1 preparação $(3,3 \% \pm 3,3)$, relativa a 1 fêmea, achamos nove vasos. assim colocados: três no quadrante cranioventral; três no quadrante caudoventral; um no quadrante caudodorsal; um sobre a linha craniocaudal, entre os quadrantes cranioventral e caudoventral e um sobre a linha dorsoventral entre os quadrantes cranioventral e craniodorsal.

7. Em 1 peça $(3,3 \% \pm 3,3)$, retirada de 1 macho, computamos onze vasos, situados deste modo: quatro no quadrante cranioventral; três no quadrante caudoventral; dois no quadrante caudodorsal e dois sobre a linha dorsoventral, entre os quadrantes cranioventral e craniodorsal.

\section{B. Ramos justahilares}

1. Em 8 dissecçōes $(26.7 \% \pm 8,1)$, referentes a 5 fêmeas e 3 machos, patenteamos dois vasos, distribuidos como se segue:

a. quadrante cranioventral - um vezes, dois -1 vez;

b. quadrante craniodorsal - um -1 vez;

c. quadrante caudoventral - um -4 vezes, dois -2 vezes; d. linha dorsoventral - entre os quadrantes cranioventral e craniodorsal, um - 1 vez.

2. Em 8 órgãos $(26,7 \% \pm 8,1)$, pertinentes a 4 fémeas e 4 machos, reconhecemos quatro vasos, localizados desta forma:

a. quadrante cranioventral - um - 1 vez, dois -2 vezes, três -3 vezes, quatro -1 vez:

b. quadrante craniodorsal - três -1 vez;

c. quadrante caudorentral - um -3 vezes, dois -1 vez, trés -1 vez;

d. quadrante caudodorsal - um -1 vez;

e. linha dorsoventral - entre os quadrantes cranioventral e craniodorsal, um -2 vezes.

3. $\operatorname{Em} 7$ casos $(23,3 \% \pm 7,7)$, correspondentes a 4 fêmeas e 3 machos, contamos três vasos, assim postados:

a. quadrante cranioventral - um -2 vezes, dois -4 vezes, três -1 vez;

b. quadrante caudoventral - um -5 vezes;

c. linha craniocaudal - entre os quadrantes cranioventral e caudoventral. um -2 vezes;

d. linha dorsoventral - entre os quadrantes cranioventral e craniodorsal, um - 1 vez.

4. Em 4 rins $(13,3 \% \pm 6.2)$, relativos a 3 fémeas e 1 macho, registramos um vaso, disposto do seguinte modo:

a. quadrante cranioventral -3 vezes;

b. quadrante caudoventral - 1 vez.

5. Em 2 preparações $(6,7 \% \pm 4,6)$, pertencentes a 1 fémea e 1 macho, assi- 


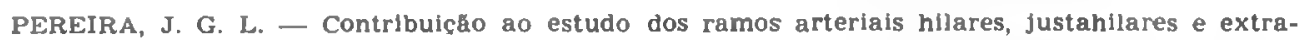
hllares em rins de cavalos (Equus caballus). Rev. Fac. Med. vet. Zootec. Univ. S. Paulo, $11: 237-61,1974$.

nalamos cinco vasos, colocados desta maneira:

a. quadrante cranioventral - dois -1 vez, cinco - 1 vez;

b. quadrante caudoventral - dois -1 vez;

c. quadrante caudodorsal - um -1 vez.

6. $\operatorname{Em} 1$ peça $(3,3 \% \pm 3,3)$, retirada de 1 fêmea, vimos seis vasos, situados: cinco no quadrante sranioventral e um no quadrante caudoventral.

C. Ramos extrahilares

1. Em 4 dissecçōes $(13,3 \% \pm 6,2)$, todas de fêmeas, notamos três vasos, distribuídos como se segue:

a. quadrante cranioventral - dois -2 vezes, três -2 vezes;

b. linha craniocaudal - entre os quadrantes cranioventral e caudoventral, um - 1 vez;

c. linha dorsoventral - entre os quadrantes cranioventral e craniodorsal, um -1 vez.

2. Em 4 órgāos $(13,3 \% \pm 6,2)$, referentes a 1 fêmea e 3 machos, achamos cinco vasos, assim localizados:

a. quadrante cranioventral - quatro 1 vez, cinco -3 vezes;

b. quadrante caudoventral - um - 1 vez.

3. Em 4 casos $(13,3 \% \pm 6,2)$, pertinentes a 3 fêmeas e 1 macho, computamos seis vasos, postados desta forma:

a. quadrante cranioventral - cinco - 3 vezes, seis -1 vez;

b. quadrante craniodorsal - um -1 vez; c. quadrante caudoventral - um - 2 vezes.

4. Em 3 rins $(10,0 \% \pm 5,5)$, correspondentes a 1 fêmea e 2 machos, patenteamos sete vasos, dispostos do seguinte modo:

a. quadrante cranioventral - seis -2 vezes, sete -1 vez;

b. quadrante caudoventral - um -2 vezes.

5. Em 2 preparaçōes $(6,7 \% \pm 4,6)$, ambas de fêmeas, reconhecemos um vaso no quadrante cranioventral.

6. Em 2 peças $(6,7 \% \pm 4,6)$, de machos. contamos dois vasos, colocados como se segue:

a. quadrante cranioventral - um -2 vezes;

b. quadrante caudoventral - um -1 vez;

c. linha dorsoventral - entre os quadrantes caudoventral e caudodorsal, um -1 vez.

7. Em 2 dissecçōes $(6,7 \% \pm 4,6)$, relativas a 1 fêmea e 1 macho, registramos quatro vasos situados no quadrante cranioventral.

8. Em 2 órgāos $(6,7 \% \pm 4,6)$, pertencentes a 2 fêmeas, assinalamos dez vasos, distribuidos desta maneira:

a. quadrante cranioventral - oito - 1 vez, nove - 1 vez;

b. quadrante caudoventral - um - 1 vez, dois -1 vez.

9. $\operatorname{Em} 1$ caso $(3,3 \% \pm 3,3)$, retirado de 1 macho, vimos oito vasos: seis no quadrante cranioventral, um no quadrante craniodorsal e um no quadrante caudoventral. 
PEREIRA, J. G. L. - Contrlbulçao ao estudo dos ramos arterials hllares, justahllares e extrahllares em rlns de cavalos (Equus caballus). Rev. Fac. Med. vet. Zootec. Univ. S. Paulo, $11: 237-61,19 \% 4$

10. Em 1 rim $(3,3 \% \pm 3,3)$ referente a 1 fêmea, notamos nove vasos, no quadrante cranioventral.

11. Em 1 preparação $(3,3 \% \pm 3,3)$, pertinente a 1 fêmea, achamos onze vasos no quadrante cranioventral.

12. Em 1 peça $(3,3 \% \pm 3,3)$, correspondente a 1 fêmea, computamos doze vasos no quadrante cranioventral.

13. Em 1 dissecção $(3,3 \% \pm 3,3)$, relativa a 1 macho, patenteamos treze vasos: onze no quadrante cranioventral, um no quadrante caudoventral e um no quadrante caudodorsal.

14. Em 1 órgão $(3,3 \% \pm 3,3)$, pertencente a 1 fêmea, reconhecemos quatorze vasos no quadrante cranioventral.

15. Em 1 caso $(3,3 \% \pm 3,3)$, concernente a 1 macho, contamos dezoito vasos: dezesseis no quadrante cranioventral, um no quadrante craniodorsal e um na linha dorsoventral, entre os qua. drantes cranioventral e craniodorsal.

Devemos salientar, ainda, que não registramos a presença de ramos arteriais hilares ros quadrantes: cranioventral 3 vezes: caudoventral - 3 vezes; caudodorsal - 18 vezes e craniodorsal - 20 vezes.

De outra parte, assinalou-se a ausência de ramos justahilares nos quadrantes: cranioventral -5 vezes; caudoventral - 11 vezes; craniodorsal -28 vezes e caudodorsal -28 vezes.

Enfim, inexistiam ramos arteriais extrahilares nos quadrantcs: caudoventral -20 vezes; craniodorsal -27 vezes e caudodorsal -29 vezes.

D. Comportamento global dos ramos hilares da artéria renal esquerda, tomados isoladamente
Com referência à localização dos ramos hilares da artéria renal esquerda, cabe-nos esclarecer que os encontramos a pcnetrarem: prevalentemente na periferia da regiāo, 15 vezes $(50,0 \% \pm 9,1)$; $\mathrm{cm}$ maior número no centro, 7 vezes $(23,3 \% \pm 7,7)$; apenas na periferia, 5 vezes $(16,7 \% \pm$ $6,8)$; equivalentemente no centro e na periferia, 3 vezes $(10,0 \% \pm 5,5)$.

E. Comportamento global dos ramos justahilares da artéria renal esquerda, tomados isoladamente

Quanto aos ramos justahilares da artéria renal esquerda, achamo-los postados: predominantemente no centro da zona que lhes corr sponde, 10 vezes $(33,3 \% \pm 8,6)$; em maior númcro na periferia, 8 vezes $(26,7 \% \pm 8,1)$; igualmente repartidos, 5 vezes $(16,7 \% \pm 6,8)$; unicamente na periferia 4 vezes; exclusivamente no centro, 3 vezes $(10,0 \% \pm 5,5)$.

F. Comportamento globul dos ramos extrahilares du artéria renal esquerda, tomados isoladamente

Com relação aos ramos extrahilares da artéria renal esquerda, computamo-los a entrarem em maior número nos distritos centrais do respectivo território, 15 vezes $(50,0 \% \pm 9,1)$; somente no centro, 7 vezes $(23,3 \% \pm 7,7)$; prevalcntemente na periferia, 6 vezes $(20,0 \% \pm 7,3)$; equivalentemente no centro e na periferia, 2 vezes $(6,7 \% \pm 4,6)$.

Pela análise estatistica (coeficiente de Pcarson), assinalamos correlação positiva entre o nümero de ramos arteriais hilares, justahilares e extrahilares, para os rins direito e esquerdo, independentemente do sexo.

\section{COMENTARIOS}

Os resultados que acabamos de concatenar, em confronto com as informaçōes 
PEREIRA, J. G. L. - Contribuiçáo ao estudo dos ramos arteriais hllares, justahilares e extrahilares em rins de cavalos (Equus caballus). Rev. Fac. Med. vet. Zootec, Univ. S. Paulo, 11 : 237-61, 1974 .

colhidas nos compêndios de Anutomia Veterinária, năo permitem, como ê fácil entender, teçamos mais do que algumas considerações de caráter genérico.

Com efeito, a alusão de vários AA. (ZANOLLI ${ }^{2}$ - 1910; BOURDELLE \& BRESSOU ${ }^{2}$ - 1937; MASSUI 21 - 1960; GONZÁLEZ Y GARCIA \& ALVAREZ 12 - 1961) à presença da artéria renal indivisa, destoa integralmente dos achados correspondentes às nossas peças, que a exibem, sempre, a ramificar-se antes de atingir o órgão.

Certos tratadistas, esclareça-se, fazem menção à ocorrência de inconstante número de ramos endereçados ao rim, por aquele vaso: falam em dois ou três (CARADONNA ${ }^{6}-1930$; FAVILLI ${ }^{10}-1931$; BOSSI ${ }^{1}$ - s.d.), quatro a seis (MANNU 18 - 1930), cinco a oito (GURLT'S ${ }^{13}$ 1873); ELLENBERGER \& BAUM ${ }^{*}-$ 1932; BRUNI \& ZIMMERL 5 - 1947; SISSON \& GROSSMAN 27 - 1959; SCHWARZE \& SCHRODER 2 - 1972) e seis a oito (BRADLEY ' - 1922); tais dados, aliás, traduzem, expressivamente, a reinante disparidade de opiniōes.

De outra parte, muitos livros de texto (FRANCK 11 - 1883; MONGIARDINO 22 - 1903; MARTIN 19 - 1904; MARTIN 20 - 1915; MONTANE \& BOURDELLE 23 1913; LEPOUTRE $16-1921$; LESBRE 17 - 1923; SCHMALTZ ${ }^{24}-1928$; BOURDELLE \& BRESSOU ${ }^{3}-1938$; ZIMMERL 29 - 1949; SCHUMMER \& NICKEL 25 1960; DOBBERSTEIN \& HOFFMANN 7 1963; DOBBERSTEIN \& HOFFMANN \& - 1963; KOCH 11 - 1963; KOCH $15-$ 1965), sequer se preocupam com esse importante pormenor, limitando-se a apontar a existência de diversos ramos.

Diante do exposto, parece oportuno realçar, desde logo, que em nossas dissecções nunca a artéria renal se evidencia de maneira descrita pelo primeiro grupo de AA., ou seja, indivisa. Não a vimos, também, a fornecer dois, três, quatro ou cinco ramos e somente 4 casos mostravam-na a resolver-se em seis ( 1 vez $-3,3 \%$ ), sete (1 vez $-3,3 \%$ ) e oito ( 2 vezes $-6,7 \%$ ), opostamente ao estabelecido pelo segundo grupo.

Melhor explicitando, identificamos, à dirsita, de seis a vinte e quatro e, à esquarda, de oito a vinte e seis ramificaçōes da artéria renal, tendo sido computado, com maior freqüência e por ordem descrescente, respectivamente, o seguinte número delas: nove ( 4 vezes - 13,3\%), onze ( 3 vezes $-10,0 \%$ ), dezesseis ( 3 vezes $-10,0 \%)$, vinte ( 3 vezes $-10,0 \%)$, dez ( 2 vezes $-6.7 \%$ ), quinze ( 2 vezes $6.7 \%)$, vinte um ( 2 vezes $-6,7 \%)$, treze $-23,3 \%)$, nove ( 5 vezes $-16,7 \%$ ), vinte e um ( 3 vezes $-10,0 \%$ ), oito ( 2 vezes $6.7 \%)$, dez $(2$ vezes $-6,7 \%)$ e dezessete (2 vezes $-6,7 \%$ ).

Os ramos endereçados ao rim, considerando-se bem definidos territórios de penetraçāo, mereceram, consoante decidimos, a qualificaçāo de hilares, justahilares e extrahilares.

A direita contamos três a dez vasos hilares, observando, mais ccmumente, cinco (2 vezes $-27,7 \%$ ); à esquerda identificamos três a onze, repetindo-se a preponderância de cinco (12 vezes - 40,0\%).

As ramificaçōes justahilares variam, à direita, de uma a seis (somente $\mathrm{fm}$ uma peça estāo ausentes), ocorrendo, amiude, duas (11 vezes - 36,7\%); à esquerda, surgem, do mesmo modo, de uma a seis, notando-se equivalência de preparaçōes com duas ( 8 vezes $-26.7 \%$ ) e quatro ( 8 vezes $-26,7 \%$ ).

Quanto aos ramos extrahilares, à direita, assinalamos de um a quinze, com mais incidência de cinco ( 5 vezes $-16,7 \%$ ); à esquerda, vimos de um a dezoito, com igual predominio de três ( 4 vezes $-13,3 \%$ ); 
PEREIRA, J. G. L. - Contribulçáo ao estudo dos rumos arteriais hilares, justahilares e extrahllares em rins de cavalos (Equus caballtus). Rev. Fac. Med. vet. Kootec. Univ. S. Paulo, $11: 237-61,1974$.

cinco $(4$ vezes $-13,3 \%)$ e seis ( 4 vezes $-13,3 \%$ ).

A propósito, julgamos oortuno recordar que, se a maioria dos AA. citados alude à entrada de vasos unicamente pelo hilo renal - somando, acreditamos, ramificações hilares e justahilares - outros (GURLT'S ${ }^{13}$

- 1873; FRANCK 11 - 1883; MARTIN 19 - 1904; MARTIN 20 - 1915; BRADLEY + - 1922; LESBRE 17 - 1923; SCHMALTZ 21 - 1928; ELLENBERGER \& BAUM 9 1932; SISSON \& GROSSMAN 27 - 1959; SCHWARZE \& SCHRODER 26 - 1972) indicam a chegada dessas entidades à face ventral do órgão (ramificações extrahilares). Nenhum, entretanto, faz referência ao envio de vasos para a face dorsal, disposição por nós evidenciada, à direita (1 vez - 3,3\%) e à esquerda (10 vezes $33,3 \%$ ).

Examinada, conjuntamente, a situaçāo dos ramos das artérias renais, de posição hilar, Justahilar e extrahilar, fato de que os tratadistas também nāo se ocupam, reconhecemos, no tocante as regiōes por onde se verifica a entrada desses vasos, as seguintes disposiçōes:

a. ramos hilares - prevalentemente centrais, 3 vezes à direita $(10,0 \%)$ e 7 vezes à esquerda (23,3\%); em maior número periféricos, 18 vezes à direita $(60,0 \%)$ e 15 vezes à esquerda $(50,0 \%)$; equitativamente centrais e periféricos, 6 vezes à direita $(20,0 \%)$ e 3 vezes à esquerda (10,0\%); exclusivamente centrais, 1 vez à direita (3,3\%); unicamente periféricos, 2 vezes à direita $(6,7 \%)$ e 5 vezes à esquerda $(16,7 \%)$;

b. ramos justahilares - predominantemente centrais, 10 vezes à direita $(33,3 \%)$ e 10 vezes à esquerda $(33,3 \%)$; prevalentemente periféricos, 8 vezes à direita $(26,7 \%)$ e 8 vezes à esquerda $(26,7 \%)$; igualmente centrais e periféricos, 6 vezes, à direita $(20,0 \%)$ e 5 vezes à esquerda $(16,7 \%)$; apenas centrais, 2 vezes à direita $(6,7 \%)$ e 3 vezes à esquerda $(10,0 \%)$; somente periféricos, 3 vezes à direita $(10,0 \%)$ e 4 vezes à esquerda $(13,3 \%)$;

c. ramos extrahilares - em maior número centrais, 13 vezes à direita $(43,3 \%)$ e 15 vezes à esquerda $(50,0 \%)$; predominantemente periféricos, 3 vezes à díreita $(10,0 \%)$ e 6 vezes à esquerda $(20,0 \%)$; equivalentemente centrais e periféricos, 4 vezes à direita $(13,3 \%)$ e 2 vezes à esquerda $(6.7 \%)$; exclusivamente centrais, $10 \mathrm{ve}$ zes à direita $(33,3 \%)$ e 7 vezes à esquerda $(23,3 \%)$.

Em seis pares de rins $(20,0 \%)$, complementando, registramos igual número de vasos, bilateralmente.

\section{CONCLUSOES}

Após pesquisar 60 rins, retirados de 30 cavalos, sem raça definida, adultos (12 machos e 18 fêmeas), objetivando estudar - número e os locais de penetração dos ramos hilares, justahilares e extrahilares. chegamos às conclusỏes adiante discriminadas.

1. Identificamos cinco $(26,7 \%)$, quatro $(23,3 \%)$, três $(13,3 \%)$, nove $(10,0 \%)$, dez $(10,0 \%)$, seis $(6,7 \%)$, e oito $(3,3 \%)$ ramos da artéria renal direita a entrarem na região hilar; à esquerda, assinalamos cinco $(40,0 \%)$, quatro $(20,0 \%)$, três $(16,7 \%)$, seis $(13,3 \%)$, sete $(3,3 \%)$, nove $(3,3 \%)$ e onze $(3,3 \%)$.

2. Contamos dois $(36,7 \%)$, três $(23,3 \%)$, um $(13,3 \%)$, quatro $(10,0 \%)$, cinco $(6,7 \%)$, seis $(6,7 \%)$ ramos da artéria renal direita a ocuparem posição justahilar; à esquerda, vimos dois $(26,7 \%)$, quatro $(26,7 \%)$, três $(23,3 \%)$, um $(13,3 \%)$, cinco $(6,7 \%)$ e seis $(3,3 \%)$. Apenas em 1 caso $(3,3 \%)$, à direita, inexistiam vasos justahilares.

3. Computamos cinco $(\mathbf{1 6 , 7 \% )}$, dois $(13,3 \%)$, um $(10,0 \%)$, três $(10,0 \%)$, treze 
PEREIRA, J. G. I. - Contribuição ao estudo dos ramos arteriais hilares, justahilares e extrahilares em rins de cavalos (Equus caballus). Rev. Fac. Med. vet. Zootec. Univ. S. Paulo, 11:237-61, 1974.

$(10,0 \%)$, quatro $(6,7 \%)$, seis $(6,7 \%)$, oito $(6,7 \%)$, nove $(6,7 \%)$, sete $(3,3 \%)$, dez $(3,3 \%)$, doze $(3,3 \%)$ e quinze $(3,3 \%)$ ramos da artéria renal direita a aprofundarem-se na zona extrahilar; à esquerda, registramos três $(13,3 \%)$, cinco $(13,3 \%)$, seis $(13,3 \%)$, sete $(10,0 \%)$, um $(6,7 \%)$, dois $(6,7 \%)$, quatro $(6,7 \%)$, dez $(6,7 \%)$, oito $(3,3 \%)$, nove $(3,3 \%)$, onze $(3,3 \%)$, doze $(3,3 \%)$, treze $(3,3 \%)$, quatorze $(3,3 \%)$ e dezoito $(3,3 \%)$.

4. Na região hilar, os ramos da artéria renal sāo: prevalentemente centrais, 3 vezes $(10,0 \%)$ à direita e 7 vezes $(23,3 \%)$ à esquerda; em maior número periféricos, 18 vezes $(60,0 \%)$ à direita e 15 vezes $(50,0 \%)$ à esquerda; igualmente centrais e periféricos, 6 vezes $(20,0 \%)$ à dircita e 3 vezes $(10,0 \%)$ à esquerda; unicamente centrais, 1 vez $(3,3 \%)$ à direita; apenas periféricos, 2 vezes $(6,7 \%)$ à direita e 5 vezes $(16,7 \%)$ à esquerda.

5. Na região justahilar, os ramos da artéria renal são: predominantemente centrais, 10 vezes $(33,3 \%)$ à direita e 10 vezes $(33,3 \%)$ à esquerda; prevalentemente periféricos 8 vezes $(26,7 \%)$ à direita e 8 vezes $(26,7 \%)$ à esquerda; equitativamente centrais e periféricos, 6 vezes $(20,0 \%)$ à direita e 5 vezes $(16,7 \%)$ à esquerda; somente centrais, 2 vezes $(6,7 \%)$ à direita e 3 vezes $(10,0 \%)$ à esquerda; exclusivamente periféricos, 3 vezes $(10,0 \%)$ à direjta e 4 vezes $(13,3 \%)$ à esquerda.

6. Na região extrahilar, os ramos da artéria renal são: em maior número centrais, 13 vezes $(43,3 \%)$ à direita e 15 vezes $(50,0 \%)$ à esquerda; preponderantemente periféricos, 3 vezes $(10,0 \%)$ à direita e 6 vezes $(20,0 \%)$ à esquerda; equivalentemente centrais e periféricos, 4 vezes $(13,3 \%)$ à direita e 2 vezes $(6,7 \%)$ à esquerda; unicamente centrais, 10 vezes
$(33,3 \%)$ à direita e 7 vezes $(23,3 \%)$ à esquerda.

7. A artéria renal exibe igual número de ramos, bilateralmente, em 6 preparaçōes $(20,0 \%)$.

8. A análise estatistica, mostrou correlação positiva entre o número de ramos arteriais hilares, justahilares e extrahilares, tanto para o rim direito quanto para o esquerdo, independentemente do sexo.

\section{Esquemas}

Representação esquemática dos ramos arterlais das regiōes hilar (a), justahilar (b) e extrahilar (c), nos rins diretto (D) e esquerdo (E), de cavalos sem raça definida, machos (m) e fêmeas (f), adultos. Imaginamos os órgãos submetidos a giro de $90^{\circ}$, no sentido mediolateral.

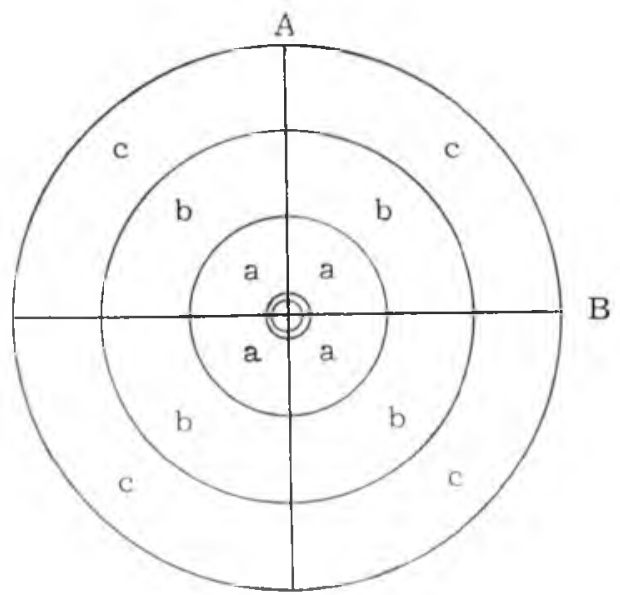

$$
\begin{aligned}
& \text { A - Iinha craniocaudal } \\
& \text { B - linha dorsoventral } \\
& \text { I - quadrante craniodorsal } \\
& \text { II - quadrante cranioventraI } \\
& \text { III - quadrante caudodorsal } \\
& \text { IV - quadrante caudoventral } \\
& \text { O - ureter } \\
& \text { - ramo arterial }
\end{aligned}
$$


PEREIRA, J. G. L. - Contribuicão ao estudo dos ramos arteriais hllares, justahliares e extrahilares em rins de cavalos (Equus caballus). Rev. Fac. Med. vet. Zootec. Univ. S. Paulo, 11 : 237-61, 1974.

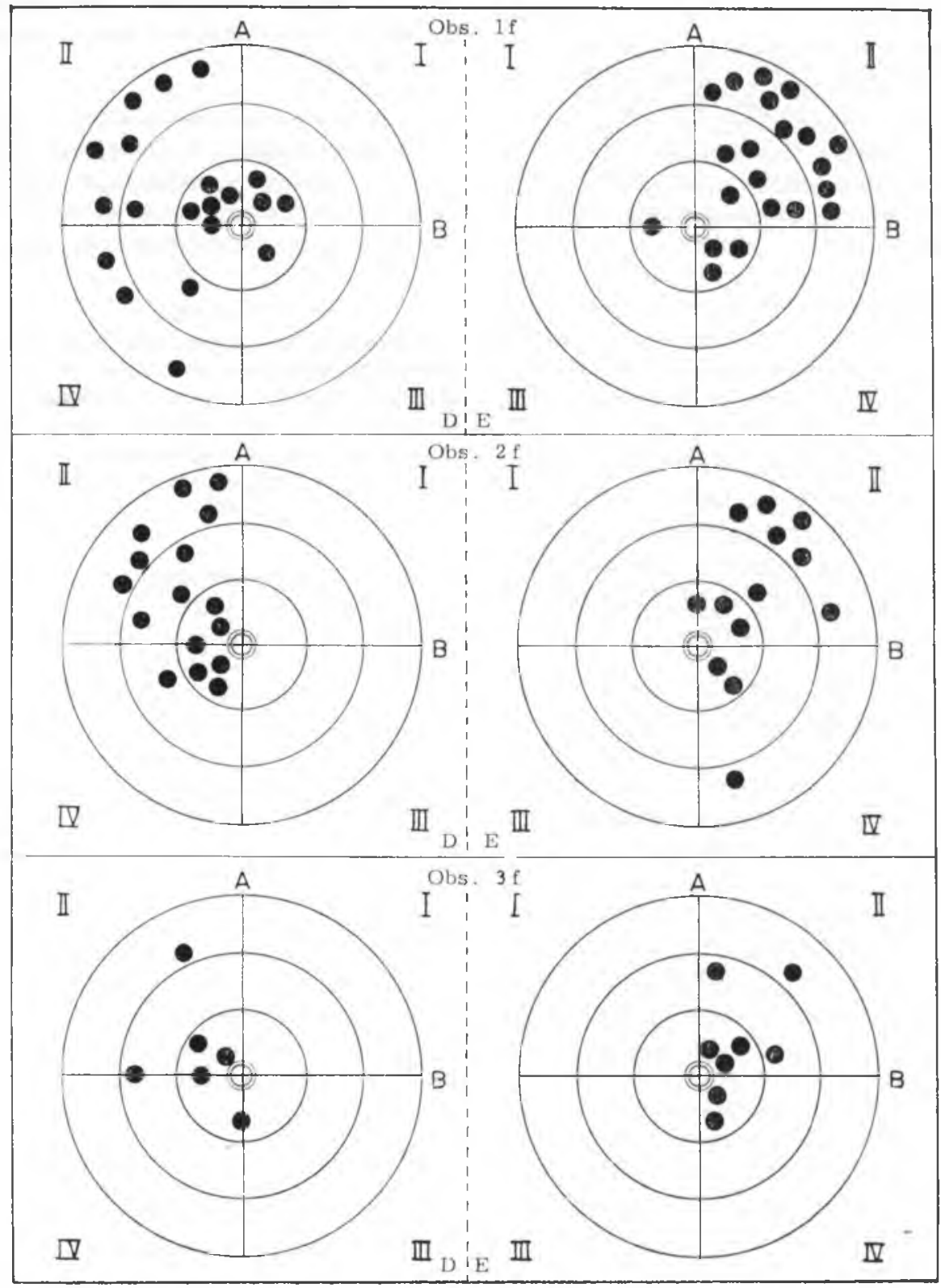


PEREIRA, J. G. L. - Contribuição ao estudo dos ramos arteriais hilares, justahilares e extrahilares em rins de cavalos (Equus caballus). Rev. Fac. Med. vet. Zootec. Univ. S. Paulo, 11:237-61, 1974

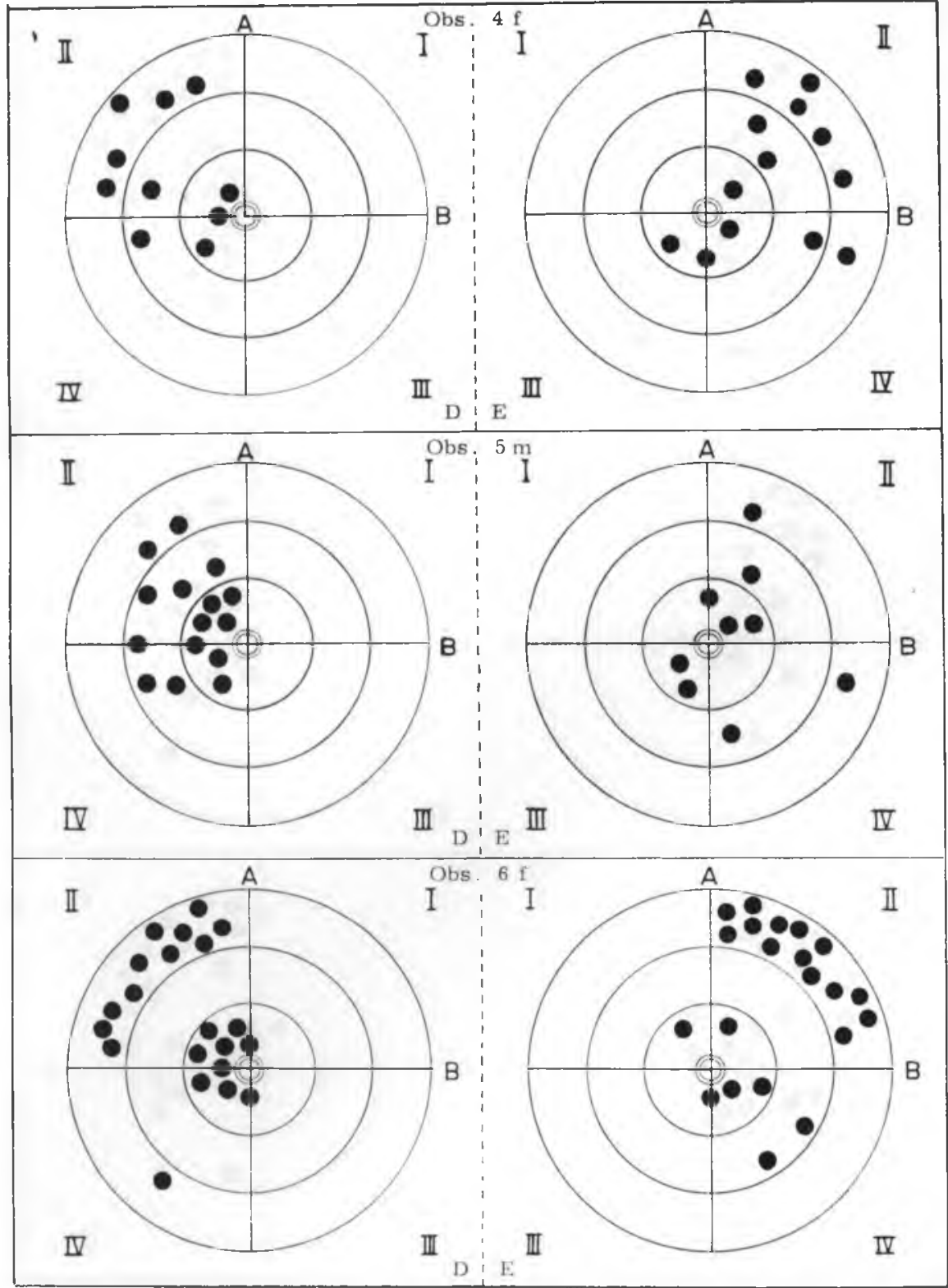


PEREIRA, J. G. L. - Contribuição ao estudo dos ramos arteriais hilares, justahilares e extrahilares em rins de cavalos (Equus caballus). Rev. Fac. Med. vet. Zootec. Univ. S. Paulo, 11:237-61, 1974 .

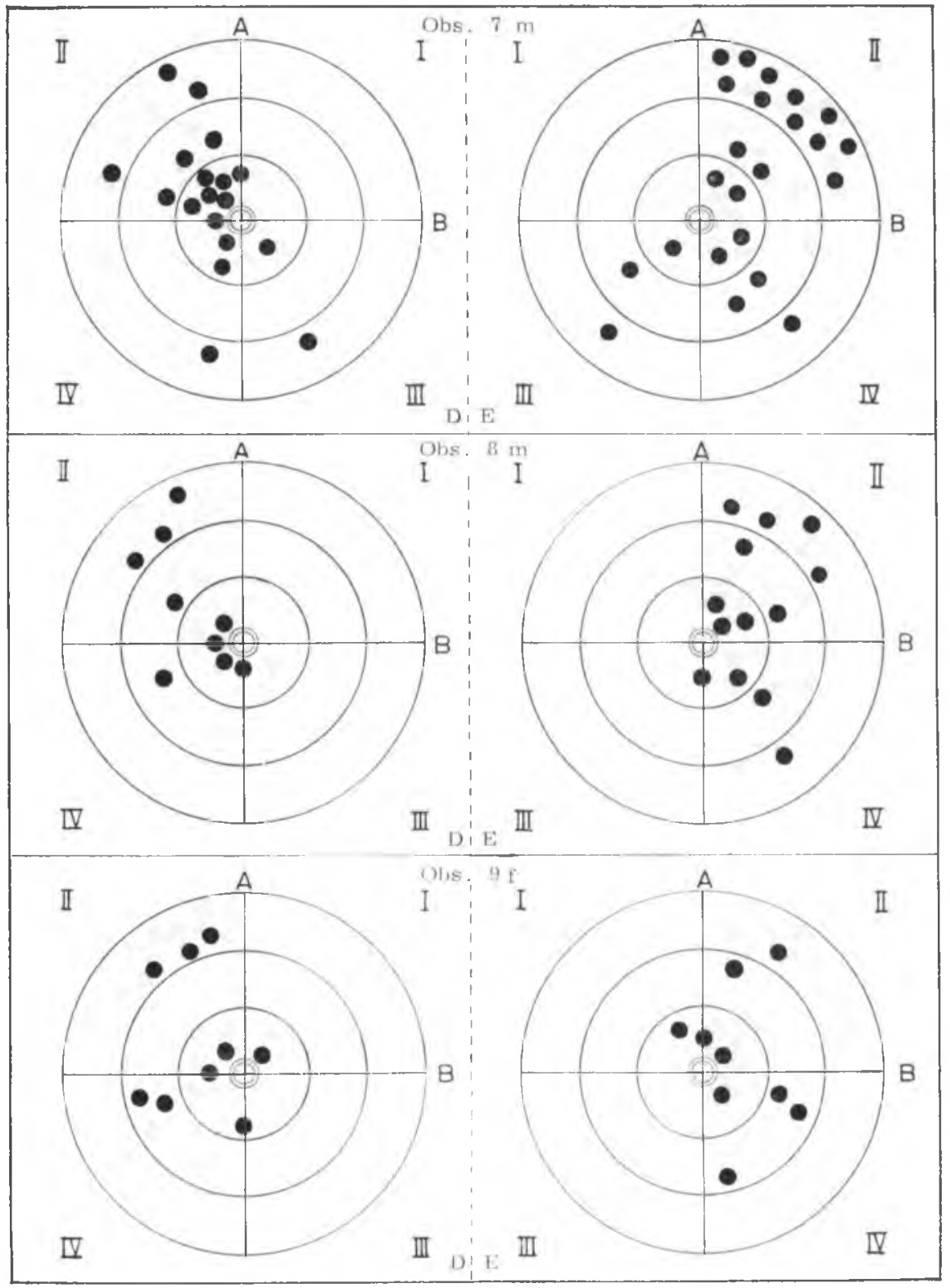


PEREIRA, J. G. L. - Contribuição ao estudo dos ramos arteriais hilares, justahilares e extrahilares em rins de cavalos (Équus caballus). Rev. Fac. Med. vet. Zootec, Univ. S. Paulo, 11:237-61, 1974 .

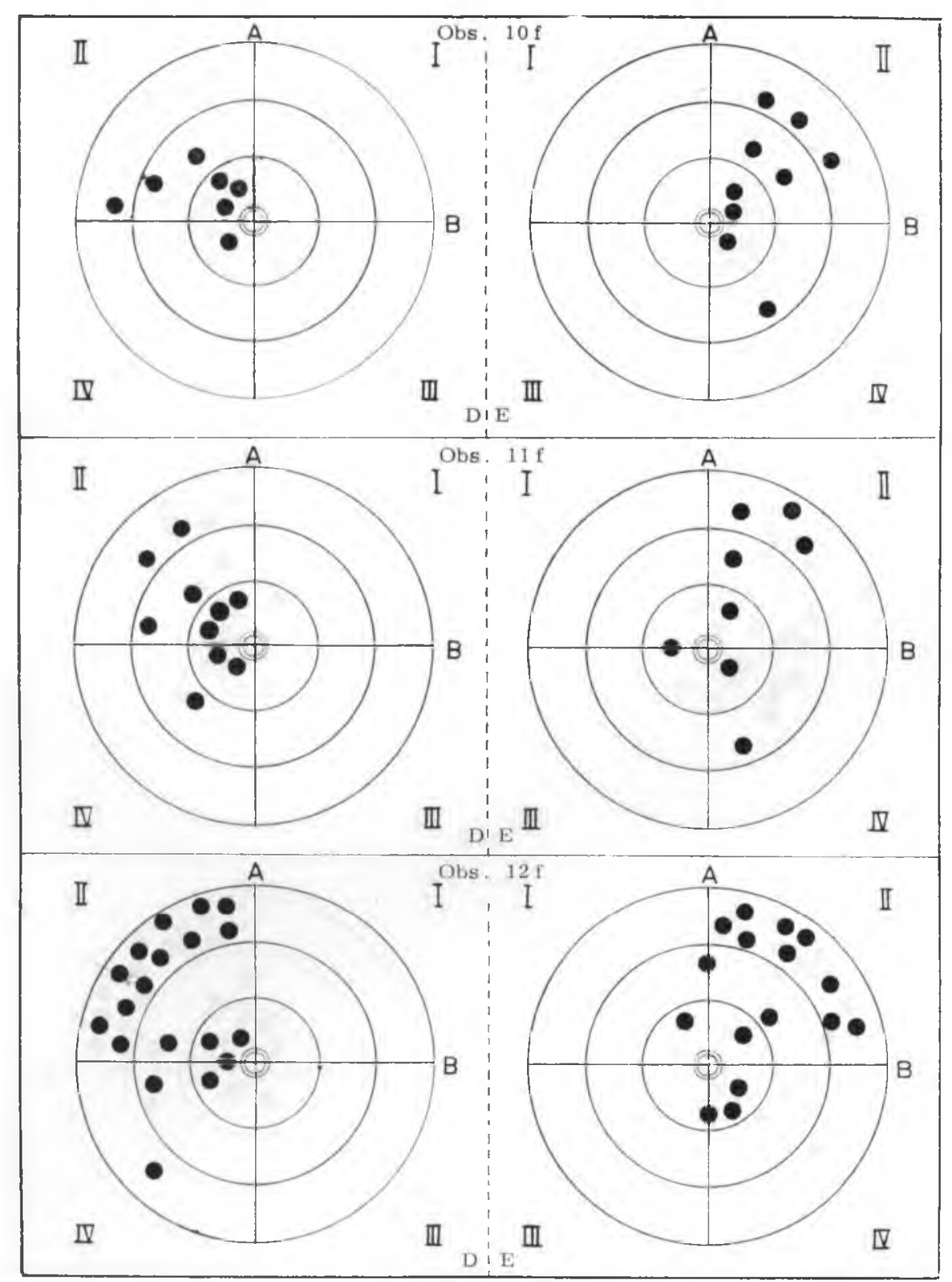


PEREIRA, J. G. L. - Contribuiçāo ao estudo dos ramos arteriais hilares, justahilares e extrahilares em rins de cavalos (Equus caballus). Rev. Fac. Med. vet. Zootec. Univ. S. Paulo, 11: 237-61, 1974 .

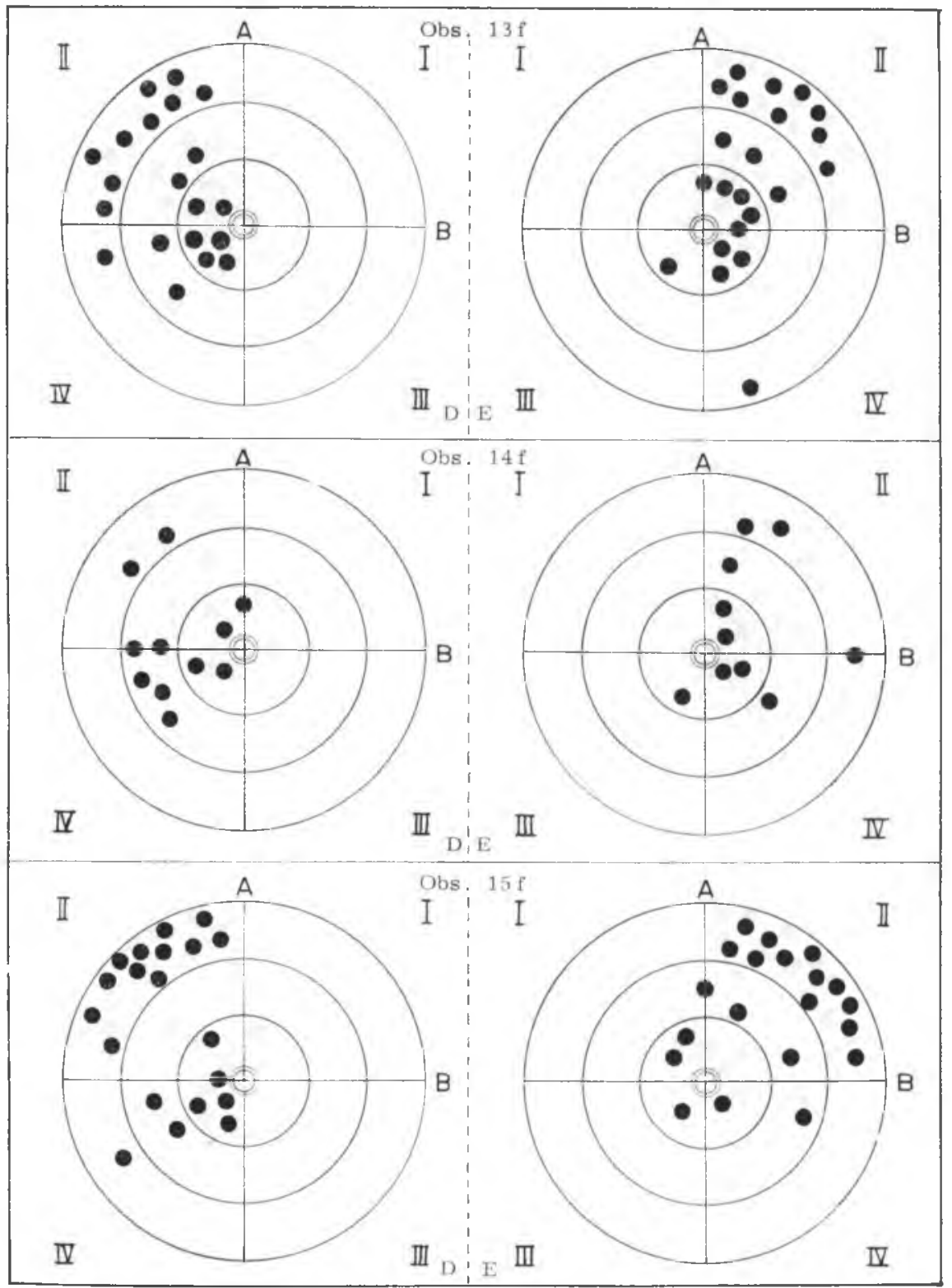


PEREIRA, J. G. L. - Contribuicão ao estudo dos ramos arteriais hilares, justahilares e extrahilares em rins de cavalos (Equus caballus). Rev. Fac. Med. vet. Zootec. Univ. S. Paulo, 11 : 237-61, 1974.

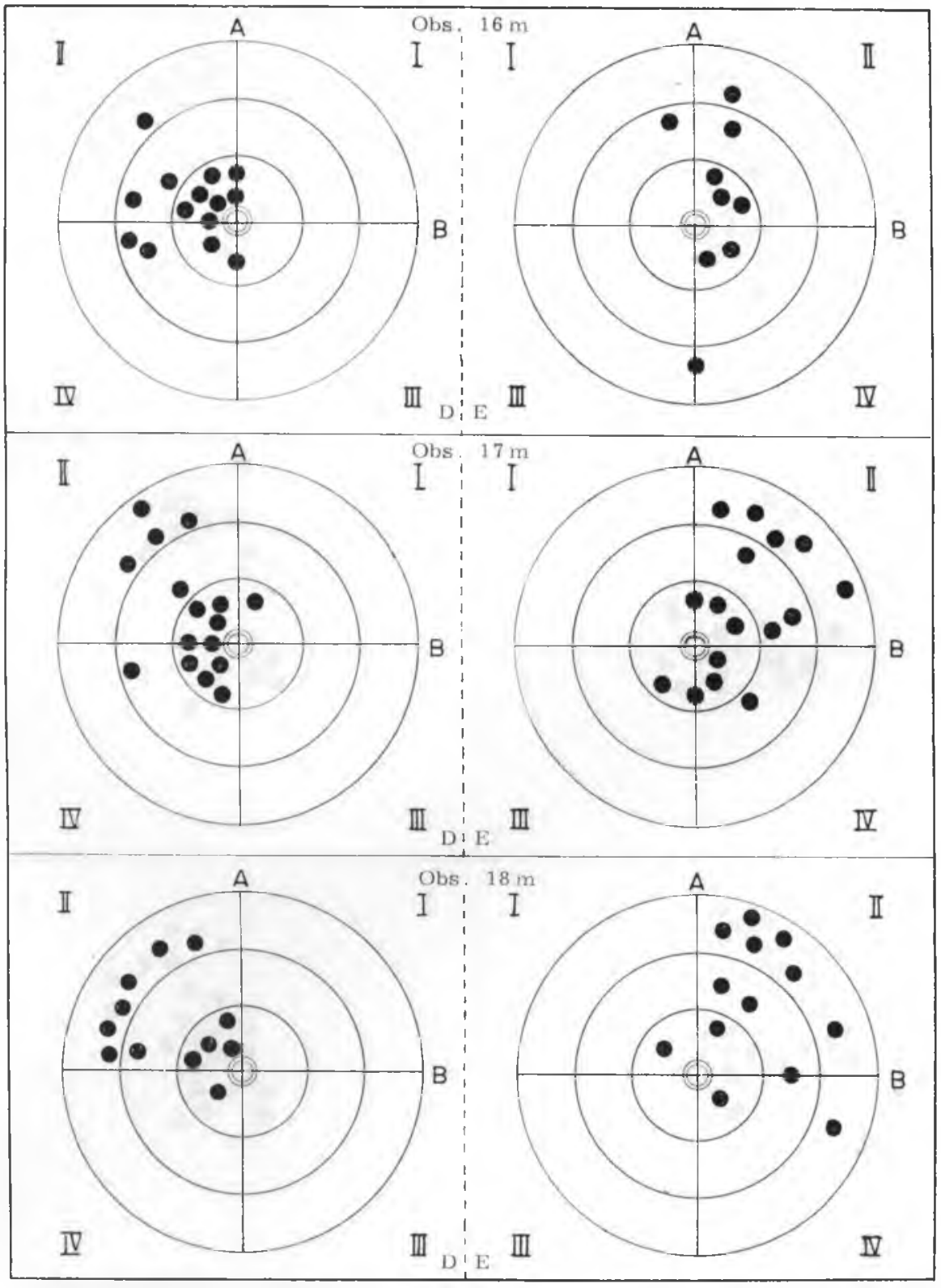


PEREIRA, J. G. L. - Contribuiçāo ao estudo dos ramos arterla!s hilares, justahilares e extrahilares em rins de cavalos (Equus caballus). Rev. Fac. Med. vet. Zootec. Univ. S. Paulo, 11:237-61, 1974

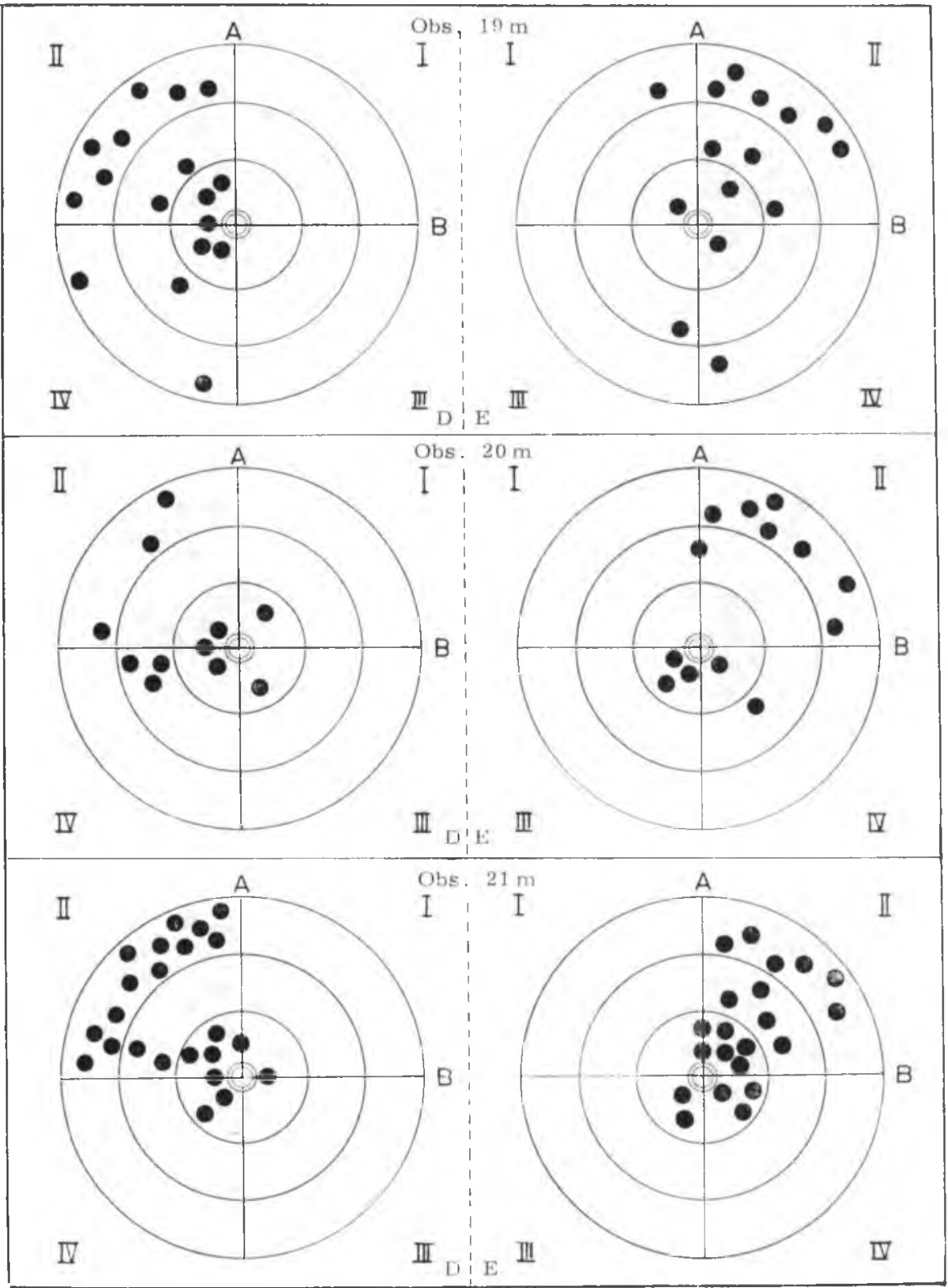


PEREIRA, J. G. L. - Contribuição ao estudo dos ramos arteriais hilares, Justahilares e extrahllares em rins de cavalos (Equus caballus). Rev. Fac. Med. vet. Zootec. Univ. S. Paulo, $11: 237-61,1974$.

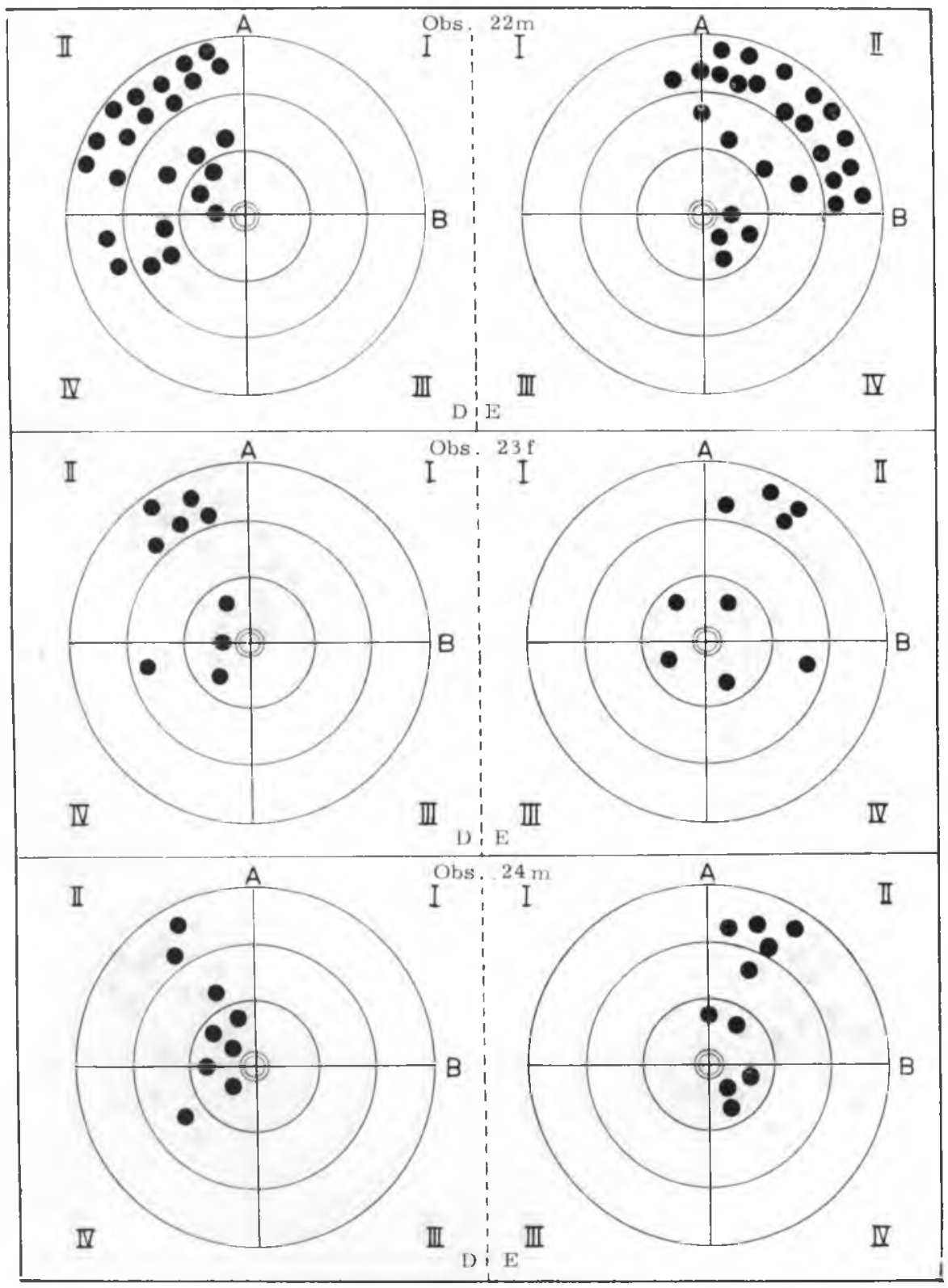


PEREIRA, J. G. L. - Contribuiçāo ao estudo dos ramos arteria's hilares, justahilares e extré hilares em rins de cavalos (Equus caballus). Rev. Fac. Med, vet. Zootec. Univ. S. Paul. $11: 237-61,1974$.

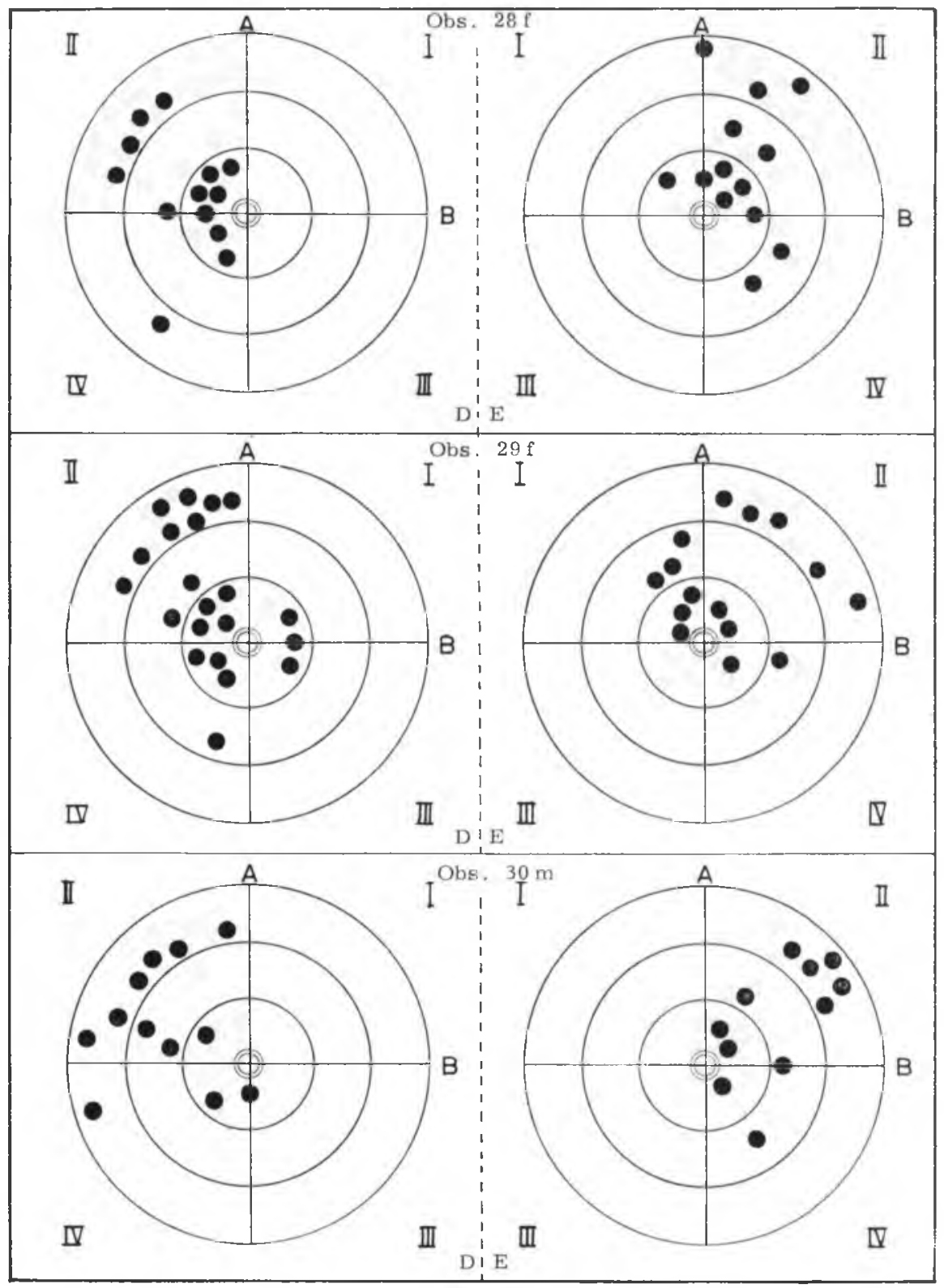


PEKEIRA, J. G. L. - Contribuiçāo ao estudo dos ramos arteriais hilares, justahilares e extrahilares em rins de cavalos (Equus caballus). Rev. Fac. Med. vet. Zootec. Univ. S. Paulo, $11: 237-61,1974$.

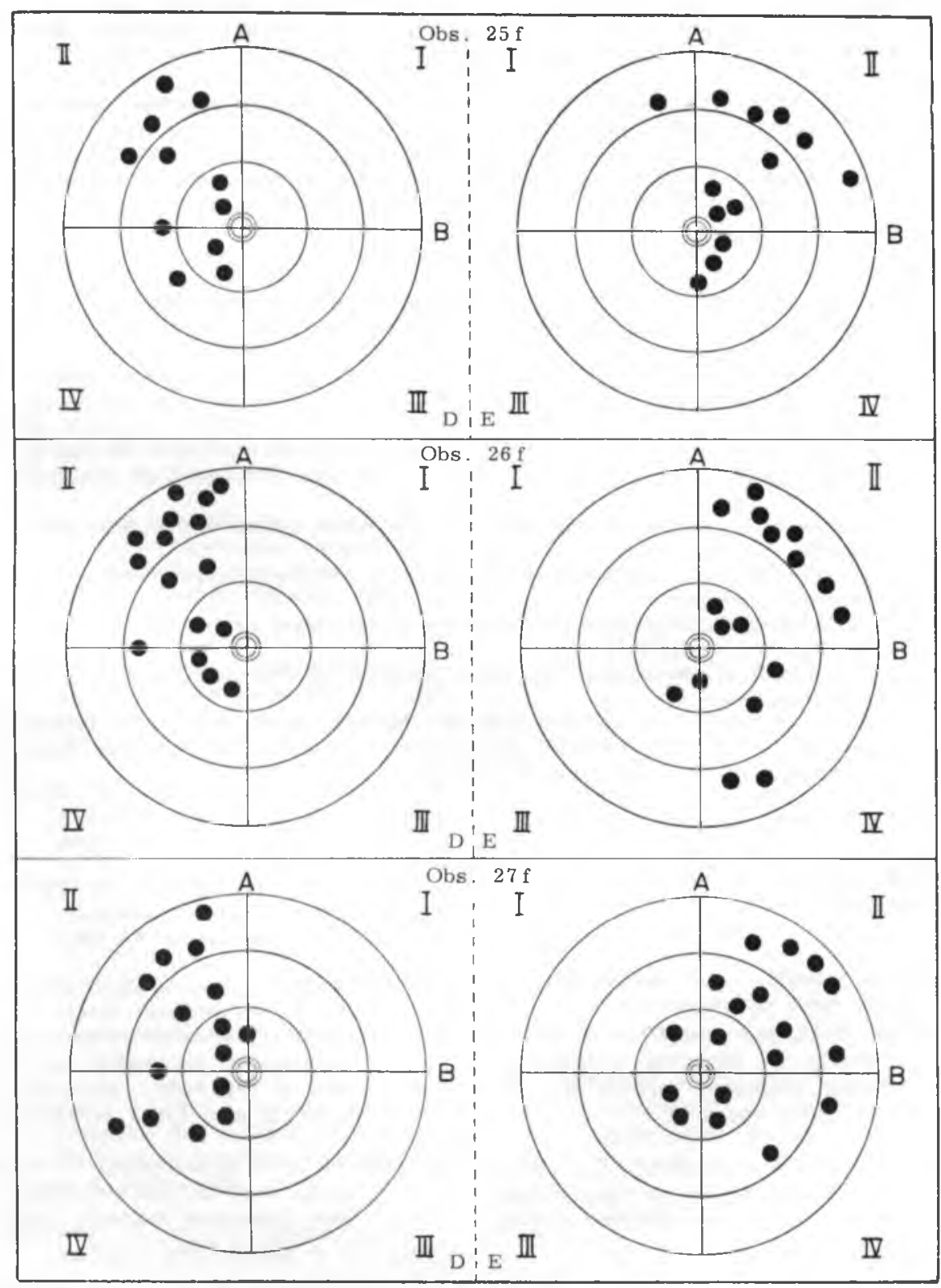


PEREIRA, J. G. L. - Contribuição ao estudo dos ramos arteriaís hilares, justahilares e extrahilares em rins de cavalos (Equus caballus). Rev. Fac. Med. vet. Zootec. Univ. S. Paulo, 11:237-61, 1974

RFMV-A/24

Pereira, J. G. L. - Contribution to the study of hilar, juxtahilar and extrahilar arterial branches in kidneys of horses (Equus caballus). Rev. Fac. Med. vet. Zootec. Univ. S. Paulo, 11:237-61, 1974.

Summary: This study is based on the exam of 30 sets including kidneys, vassels, ureteres and tracts corresponding to the aorta artery and caudal cava vein: these sets were taken from adult horses, 12 male and 18 female, and the hilar, juxtahilar and extrahilar branches of the renal artery were studied, as well as the whole behaviour of these branches taken in isolation.

The results allow the following conclusions:

1. From three to ten branches of the right renal artery enter the hilar region; and so do from three to eleven branches of the left renal artery.

2. From one to six branches of the right and left renal artcries occupy juxtahilar position. In 1 case on the right side, thcre were no juxtahilar vassels.

3. From one to fifteen branches of the right renal artery enter the extrahilar region, and so do from one to eighteen branches of the left renal artery.

4. In the hilar region the branches of the renal artery are mostly peripheric.

5. In the juxtahilar portion the branches of the renal artery are predominantly central.

6. In the extrahilar portion the branches of the renal artery are generally central.

7. The renal artery shows the same number of branches bilaterally in 6 cases.

8. There is positive correlation both to the left and to the right kidney among the number of hilar, juxtahilar and extrahilar branches independently of sex, statistically speaking.

UNITERM: Horses*; Kidneys*; Renal Artery*.

\section{REFERENCIAS BIBLIOGRAFICAS}

1. BOSSI, V. - In: BOSSI, V. et al. Trattato di anatomia veterinaria. Milano, Francesco Vallardi, s.d. v. 2, p. 207 e 797.

2. BOURDELLE, E. \& BRESSOU, C. - Anatomie régionale des animaux domestiques. Paris, J. B. Baillière et Fils, 1937. p. 72.

3. BOURDELle, E. \& BREsSOU, C. Anatomie régionale des animaux domestiques. Parls, J. B. Baillière et Fils, 1938. v. 1, p. 764-5.
4. BRADLEY, O. C. - The Topographical anatomy of the thorax and abdomen of the horse. Edinburgh, W. Green \& Son, 1922. p. 142 e 147.

5. BRUNI, A. C. \& ZIMMERL, V. - Anatomia degli animali domestici. Milano, Francesco Vallardi, 1947. v. 2, p. 153 e 352 .

6. CARADONNA, G. B. - In: ZIMMERL, V. - Trattato di anatomia veteriria. Milano, Francesco Vallardi, 1930. v. 3, p. 15 . 
PEREIRA, J. G. L. - Contribuição ao estudo dos ramos arteriais hilares, justahilares e extrahilares em rins de cavalos (Equus caballus). Rev. Fac. Med. vet. Zootec. Univ. S. Paulo, $11: 237-61,1974$.

7. DOBBERSTEIN, J. \& HOFFMANN, G. - Lerbuch der vergleichenden Anatomie der Haustiere. Leipzig, $\mathbf{S}$. Hirzel, 1963. v. 2, p. 136.

8. DOBBERSTEIN, J. \& HOFFMANN, G. - Lerbuch der vergleichenden Anatomie der Haustiere. Leipzig, S. Hirzel, 1963. v. 3, p. 50 .

9. ELLENBERGER, W. \& BAUM, H. Handbuch der vergleichenden Anatomie der Haustiere. 17 Auf. Berlin, Julius Springer, 1932. p. 696

10. FAVILLI, N. - Nozioni comparate di anatomia e fisiologia degli animali rurali. Torino, Unione Tipografico - Editrice Torinese, 1931. p. 400 e 449 .

11. FRANCK, L. - Handbuch der Anatomie der Haustiere. Stuttgart, Schickhardt \& Ebner, 1883. p. 872.

12. GONZALEZ Y GARCIA, J. \& ALVAREZ, R. G. - Anatomia comparada de los animales domesticos. $7 .^{\mathrm{a}}$ ed. Madrid, Grafica Canales, 1961. p. 631.

13. GURLT'S, E. F. - Handbuch der vergleichenden Anatomie der Haus-Säugethiere. Berlin, August Hirschwald, 1873. p. 620 .

14. KOCH, T. - Lehrbuch der Veterinär Anatomie. Jena, Gustav Fischer, 1963. v. 2, p. 234 .

15. KOCH, T. - Lehrbuch der Veterinär Anatomie. Jena, Gustav Fischer, 1965. v. 3, p. 119 .

16. LEPOUTRE, L. - Notes du cours d'ana. tomie comparée des animaux domestiques. Gemblaux, J. Duculot, 1921. p. 164 .

17. LESBRE F. X - Précis d'anatomie comparée des animaux domestiques. Paris, J. B. Ballière et Fils, 1923. v. 2, p. 78 e 338 .

18. MANNU, A. - In: ZIMMERL, V. Trattato di anatomia veterinária.
Milano, Francesco Vallardi, 1930. v. 2, p. 168 .

19. MARTIN, P. - Lerbuch der Anatomie der Haustiere. Stuttgart, Schickhardt \& Ebner, 1904. p. 694, 861.

20. MARTIN, P. - Lehrbuch der Anatomie der Haustiere. Stuttgart, Schickhardt \& Ebner, 1915. v. 2, p. 172

21. MASSUI, K. - Anatomia comparada dos animais domésticos. 10. ed. Tokio, Yokendo, 1960. v. 1, p. 189.

22. MONGIARDINO, T. - Trattato di anatomia topografica dei mamiferi domestici. Torino, Luigi Delgrosso, 1903. p. 192.

23. MONTANE, L. \& BOURDELlE, E. Anatomie régionali des animaux domestiques. Paris, J. B. Ballltère et Fils, 1913. v. 1, p. 862 .

24. SCHMALTZ, R. - Anatomie des Pferdes. Berlin, Richard Schoetz, $1928 . p$. 505 .

25. SCHUMBER, A. \& NICKEL, R. - In: NICKEL, R. et als. - Lehrbuch der Anatomie der Haustiere. Berlin, Paulo Parey, 1960. v. 2, p. 290.

26. SCHWARZE, E. \& SCHRODER, L. Compendio de Anatomia Veterinaria. Zaragoza, Acribia, 1972. v. 3, p. 72.

27. SISSON, S. \& GROSSMAN, J. D. - Anatomia de los animales domesticos. Barcelona, Salvat Editores, 1959. p. 550 e 658 .

28. ZANOLLI, C. - Manual di Anatomia Veterinaria. La Plata, Félix F. Sant1, 1910. v. 1, p. 382.

29. ZIMMERL, V. - Anatomia topografica veterinaria. Milano, Francesco Vallardi, 1949. p. 352.

Recebído para publicação em 20-8-74 Aprovado para publicação em 29-8-74 